\title{
ZAKAT UNTUK PEMBERDAYAAN EKONOMI MUSTAHIK DI BAZNAS KABUPATEN KUANTAN SINGINGI RIAU
}

\author{
Fitrianto \\ Universitas Islam Kuantan Singingi (UNIKS) Riau \\ e-mail: fitriuniks1976@gmail.com
}

\begin{abstract}
Zakat in Islam is a treasure worship and zakat is the obligation of Muslims who already have wealth to meet the value of nisab and haul which must be distributed to Asnaf directly or through zakat institution. National Amil Zakat Agency (BAZNAS) Kuantan Singingi is an official government zakat institution that has been in operation in 2007 and has raised a large amount of zakat funds. In 2015 zakat fund raising has increased significantly to reach the amount of Rp. 2,162,988,234. The accumulated zakat funds are distributed by BAZNAS Kuantan Singingi in various program models such as consumptive zakat program, health services in the form of medical aid, educational scholarships, and habitable housing development for asnaf, and productive zakat programs such as asnaf skills training and venture capital in various businesses. These programs are proclaimed to improve the mustahik welfare in Kuantan Singingi district of Riau.
\end{abstract}

Keywords: Zakat Funds, Economic Empowerment, BAZNAS 


\section{Fitrianto}

\section{Pendahuluan}

Islam merupakan agama universal yang mengatur berbagai aspek kehidupan manusia seperti hubungan antara yang berpunya harta dengan yang tidak berharta (hablu min nas), dan praktek ini diawal Islam sebelum Rasullah saw hijrah ke Madinah dikenal dengan sebagai anjuran Infak (Muhammad, 2002: 16), yaitu bagi mereka yang mempunyai kelebihan harta wajib membantu yang berkekurangan yang tidak ada batasan minimum dan maksimum atas pemberian tersebut. Kewajiban tersebut merupakan dasar untuk menunaikan zakat, khususnya zakat fitrah dan kewajiban zakat al-Maal (Sudarsono, 2003: 233). Zakat merupakan pemisahan sejumlah harta tertentu yang diwajibkan oleh Allah SWT untuk diberikan bagi umat Islam yang berhak menerimanya (Qardhawi, 2002: 34-35). Kewajiban berzakat ini berdasarkan perintah yang ditegaskan Allah dalam al-Quran surat at-Taubah ayat 103 yang artinya: "Ambillah zakat dari sebagian harta mereka, dengan zakat itu kamu membersihkan dan mensucikan mereka dan mendoalah untuk mereka. Sesungguhnya doa kamu itu (menjadi) ketenteraman jiwa bagi mereka. dan Allah Maha mendengar lagi Maha Mengetahui." (QS. At-Taubah: 103)

Kewajiban zakat yang ditegaskan Allah dalam firman-Nya di atas menunjukan bahwa Islam mengatur dan menegaskan masalah yang berhubungan dengan sosioekonomi dan keagamaan masyarakat terutama bagi kaum yang lemah dan berkekurangan harta harus perhatikan dengan baik dalam memenuhi kehidupan.

Al-quran juga menegaskan bahawa didalam harta kekayaan umat muslim terdapat bagian untuk diberikan untuk orang yang lema, kurang upaya dan tidak berpunya yang berani meminta dan yang tidak berani meminta-minta. Hal ini dapat kita lihat dalam al-Quran surat adz-Dzariyat ayat 19 yang artinya: "Dan pada harta-harta mereka ada hak 


\section{Zakat untuk Pemberdayaan Ekonomi ...}

untuk orang miskin yang meminta dan orang miskin yang tidak mendapat bagian (orang miskin yang tidak mendapat bagian maksudnya ialah orang miskin yang tidak meminta-minta)." (QS. Adz-Dzariyat: 19)

Sehingga Islam itu identik dengan ajaran yang menjaga hubungan silaturahmi dan kasih sayang antara sesama dan makna yang lain, Islam itu agama yang menjunjung tinggi nilai persaudaraan, saling membantu dan tolong-menolong antara yang kaya harta dengan yang tidak berpunya dan yang kuat dengan yang kurang upaya.

Pada masa Rasulullah SAW pengelolan zakat dilukan dengan cara pengumpulan zakat perorangan dan membentuk panitia pengumpul zakat. Rasululah juga menegaskan kepada para pegawainya untuk mempermudah urusan masyarakat, dalam tata kelolah zakat dengan baik dengan tidak mementingkan kepentingan sendiri sehingga melupakan hak-hak dan kepentingan fakir dan miskin (Muhammad, 2002: 34).

Hal yang sama juga diteruskan oleh Khulafah Rasyidin setelah wafatnya Rasulullah. Sebagaimana yang dilukan oleh Saidina Abu Bakar Sidik yanh menegaskan kepada umat Islam agar tidak membedakan antara solat dengan zakat karena solat kewajiban kepada Allah SWT sedangkan zakat hak Allah atas hartanya. Selain itu, beliau juga menghukum mati orang mukmin (muzakki) yang tidak menunaikan zakat pada masa pemerintahan beliau. Harta zakat pada masa ini habis dibagikan tanpa membedakan kaum dan golongan. Manakalah pada masa Umar Bin khatab, ia meneruskan kebijakan sebelumnya dan menegaskan bahwa zakat yang dibayar atau dikeluarkan harus harta yang bernilai sedang (baik) dan tidak terburuk. Umar juga langsung bertidak sebagai pengurus zakat jika 


\section{Fitrianto}

ada petugas yang diutusnya tidak berlaku adil dalam mengelolah zakat (Muhammad, 2002: 34).

Kejayaan Islam mencapai puncak terutama dalam pengelolaan zakat pada masa khalifah Umar Bin Abdul Aziz, sehingga dalam kurun waktu 30 bulan masa pemerintahannya tidak dijumpai lagi orang miskin pada masa itu. Dalam hal ini ia menegaskan bahawa meminta zakat dari orang yang kaya tidak dipandang sebagai aturan Allah SWT melainkan sebagai hak bagi setiap muslim yang miskin. Pada masa ini juga sumber-sumber zakat telah berkembang jumlahnya seperti, zakat penghasilan, hadiah, gaji pegawai, honorarium, dan harta sitaan (Muhammad, 2002: 37).

Melihat dari kejayaan Islam di atas, ini mendorong semangat Negara yang mayoritas penduduknya beragama Islam kususnya Indonesia dalam mendirikan institusi zakat dan pengelolaan zakat yang lebih baik serta dengan harapan dapat mempercepat kesejahteraan masyarakat muslim kususnya golongan asnaf.

Maka itu, pemerintah telah mendirikan institusi zakat mulai dari tingkat pusat sampai ke kabupaten kota, diantaranya Badan Amil Zakat Nasional (BAZNAS) Kabupaten Kuantan Singingi Riau yang mulai beroperasi pada tahun 2007 dan zakat yang terhimpun saat itu berjumlah Rp. 479.811.790 (Laporan BAZNAS, 2007).

Realitas yang ada menjadi suatu persoalan yang perlu suatu kajian secara komperhensif untuk melihat dan menyelasaikan persoalan yang seharusnya tidak boleh wujud di kabupaten yang mayoritas penduduknya beragama Islam tetapi masih banyak kalang asnaf yang katagori golongan fakir dan miskin. Berarti ada beberapa kemungkinan penyebab sehingga BAZNAS Kuantan Singingi belum bisa maksimal dalam pengumpulan zakat dari para muzakki, model program pendistribusian dan pendampingan juga belum maksimal serta perlunya memodifikasi program-program pada pemberdayaan 


\section{Zakat untuk Pemberdayaan Ekonomi ...}

ekonomi golongan asnaf. Oleh sebab itu, artikel ini akan menjawab persoalan bagaimana program pengumpulan dan pendistribusian dalam pemberdayaan ekonomi asnaf?

\section{Pembahasan}

\section{Kajian zakat}

Pada masa awal Islam institusi yang mengelola zakat telah wujud, yaitu Bait al-Maal sebagai bendahara pada masa Rasullullah, Khulafa al-Rasyidin, Khilafah Bani Umayyah Di Damaskus, Khilafah Bani Abbasiyah di Baghdad dan Khilafah Turki Uthmaniyyah.

Penegasan tentang pengelolaan zakat harus dilakukan oleh pemerintah atau Institusi yang rasmi negara, ini ditegaskan dalam al-Quran surat at-Taubah ayat 103 yang bermakna suatu yang datang dari yang lebih maha kuasa perintah Allah SWT kepada Rasulullah Muahammad SAW sebagai Khalifah kerajaan Islam untuk memungut zakat dari harta orang mukmin yang kaya yang telah sampai nisab dan haul-nya melalui peran aktif pemerintah maupun Institusi pengelola zakat yang resmi dibawah naungan pemerintah seperti Baitul Maal awal Islam. Maka pengelolaan zakat di Indonesia juga dikelola oleh BAZNAS yang disahkan oleh Pemerintah dengan berpedoman pada UU No 23 tahun 2011 Tentang Pengelolaan Zakat.

Pengelolaan Zakat harus dilakukan oleh pemerintah atau Institusi Zakat sebagai perpanjang tanganan dari pemerintah supaya mempermudah dalam kebijakan pemungutan zakat dari muzakki, dan agar para asnaf terdata secara akurat dengan sistematis serta memudahan pemerintah dalam mengotrol program bagi masyarakat kurang mampu yang termasuk dalam golongan asnaf fakir miskin. 


\section{Fitrianto}

Kajian tentang zakat dengan pemberdayaan asnaf telah banyak dilakukan seperti Wirawan (2008), menjelaskan dalam kajiannya Pemberdayaan Masyarakat Miskin melalui Dana Zakat, Infaq, Dan Shodaqoh terhadap Komunitas Pengrajin Tahu di Kampung Iwul, Desa Bojong Sempu, Kecamatan Parung, Kabupaten Bogor. Bahawa wang Zakat, Infaq, Dan Shodaqoh sebagai pinjaman modal usaha dan adanya pendampingan usaha kepada kelompok usaha tahu kampong Iwul dapat merubah sumber Insani. Setelah mengikuti program pemberdayaan, secara pukul rata pendapatan masyarakat usaha tahu mengalami peningkatan dan peningkatan pendapatan sesuai dengan besarnya pinjaman modal serta adanya pendapatan harian dari usaha lain juga memberi sumbangan tambahan pendapatan.

Alfiah Nur Hasanah (2005), menjelaskan bahwa pemberdayaan uang zakat yang efektif bahagi menurunkan angka kemiskinan asnaf, tidak hanya agihan uang zakat dengan model memenuhi keperluan dasar saja (kosumtif) melainkan juga uang zakat diagihkan bagi usaha perekonomian yang produktif, dan bantuan untuk pendidikan serta bantuan perubatan. Ianya berpengaruh bahagi menurunkan jumlah penganggur.

Selain itu, Usaha-usaha dalam memajukan asnaf dengan uang zakat, sehingga membolehkan asnaf miskin keluar dari kemiskinan menjadi muzakki, maka perlu adanya distribusi zakat untuk usaha produktif dan juga ianya bergantung pada tingkat kepercayaan dan profesionalitas amil/ pengurus zakat dan pendapingan. Irfan Syauqi Beik dan Didin Hafidhuddin (2005) dalam kajiannya Zakat dan Pembangunan Perekonomian Umat.

Mila Sartika (2008) dalam kajiannya Pengaruh Pendayagunaan Zakat Produktif terhadap Pemberdayaan Mustahiq pada LAZ Yayasan Solo Peduli Surakarta. Menjelaskan bahawa dana zakat yang didistribusikan dalam 


\section{Zakat untuk Pemberdayaan Ekonomi ...}

usaha produktif boleh penambahan pendapatan dan ekonomi asnaf. Model bantuan uang zakat untuk usaha produktif seperti melalui program pinjaman qard al-hasan sebagai modal usaha dan mudharabah dengan sistem pemeliharaan hewan bagi bantuan modal berupa hewan ternak. Penulis juga menegaskan bahwa semakin beser jumlah dana zakat yang didistribusikan sebagai modal untuk usaha produktif juga berdampak positif pada penambahan jumlah pendapatan asnaf.

A. Qadri Azizy (2004), menjelaskan bahwa dana zakat tidak hanya didistribusikan untuk keperluan kosumtif saja. Secara ideal ia menegaskan dana zakat sebagai sumber keuangan umat. Distribusi dana zakat bagi keperluan konsumtif hanya dalam keadaan yang darurat saja. Sedangkan bagi asnaf yang mempunyai kemampuan untuk dibimbing dan mempunyai keahlian maka distribusi dana zakat dalam usaha produktif.

Maka melihat model pengelolaan zakat pada masa moderen tak jauh berbeda dengan apa yang perna berlaku masa awal Islam. Bahwa pengelolaan zakat di bawah BAZNAS Kuantan Singingi telah mengikut garis panduan yang ditegaskan dalam Al-Quran dan hadis. Namun pengelolan zakat masa kini kurang menampakkan kesan dalam membangun ekonomi asnaf seperti yang berlaku dahulu.

\section{Sejarah BAZNAS Kuantan Singingi}

Pada awalnya BAZNAS Kuantan Singingi bernama Badan Amil Zakat (BAZ) Kab. Kuantan Singingi dan telah mulai beroperasi dalam mengelola zakat dari muzakki terhitung pada tahun 2007 dan telah berhasil mengumpulkan dana zakat sebesar Rp. 479.811.790,- dan telah disalurkan kepada asnaf sejumlah Rp. 370.976.547. Dari hasil sosialisasi dari pihak BAZNAS dan kesadaran masyarakat Kuantan Singingi dalam mengeluarkan zakat, 


\section{Fitrianto}

pengumpulan zakat pada BAZNAS Kuantan Singingi tetap menunjukkan kecenderungan yang menggembirakan dari tahun ke tahun. Pada tahun mendatang diharapkan penerimaan zakat di Kabupaten Kuantan Singingi akan lebih meningkat sehingga dapat dimaksimalkan pendistribusiannya kepada para mustahiq di Kabupaten tersebut. Tentunya hal ini juga memerlukan dukungan dari Pemerintah Daerah Kabupaten Kuantan Singingi, Kantor Kementerian Agama Kabupaten Kuantan Singingi, Kantor Wilayah Kementerian Agama Propinsi Riau, BAZNAS Propinsi Riau dan pihak-pihak lain dalam upaya pemberdayaan zakat di Kabupaten tersebut.

\section{Program penyaluran zakat BAZNAS Kuantan Singingi}

Adapun model program penyaluran zakat oleh badan amil zakat nasional (BAZNAS) kabupaten kuantan singingi sebagai berikut:

1) Kuansing Peduli, adapun program kuansing peduli adalah seperti berikut:

1. Bantuan konsumtif kepada fakir miskin menghadapi Idul Fitri

2. Bantuan terhadap bencana alam, seperti kebakaran

3. Pemberian bantuan kepada orang terlantar/ibnu sabil/musafir, dengan syarat memiliki Surat Keterangan dari Kepolisian di wilayah Kabupaten Kuantan Singingi

4. Pemberian bantuan kepada muallaf, dengan syarat:

i. Berdomisili di Kabupaten Kuantan Singingi

ii. Telah masuk Islam paling lama 1 (satu) tahun 


\section{Zakat untuk Pemberdayaan Ekonomi ...}

2) Kuansing Sejahtera, adapun program kuansing sejahtera adalah seperti berikut:

1. Pemberian modal usaha kepada pengusaha tergolong lemah (kriteria: ada kemampuan \& ada kemauan)

2. Pelatihan tenaga kerja bagi angkatan kerja kurang mampu

3. Pembangunan rumah layak huni masyarakat kurang mampu

3) Kuansing Cerdas, adapun program kuansing cerdas adalah seperti berikut:

1. Beasiswa kurang mampu kepada siswa SD, SLTP, SLTA dan Perguruan Tinggi se Kabupaten Kuantan Singingi

2. Beasiswa terhadap siswa berprestasi kurang mampu

3. Mewujudkan satu keluarga fakir dan miskin Satu Sarjana

4) Kuansing Sehat, adapun program kuansing sehat adalah seperti berikut:

1. Bantuan biaya bagi orang yang tidak mampu terutama yang tidak memiliki Jamkesmas dan Jamkesda saat berubat di RSUD Teluk Kuantan

2. Bantuan bagi penderita penyakit berbahaya dan tidak mempunyai biaya berobat

5) Kuansing Iman dan Taqwa, adapun program kuansing iman dan taqwa adalah seperti berikut:

1. Pembinaan Madrasah dan Pondok Pesantren

2. Pembinaan Tilawatil Qur'an 


\section{Fitrianto}

\section{Pengelolaan dana zakat BAZNAS Kuantan Singingi}

Badan Amil Zakat Nasional (BAZNAS) Kabupaten Kuantan Singingi dalam operasinya telah dapat mengumpulkan dana zakat sebanyak Rp. 16.668.029.168,mulai dari tahun 2010-2015 hal itu sebagaimana terlihat pada tabel berikut ini:

Tabel 1. Penerimaan zakat BAZNAS Kuantan Singingi

Tahun 2010-2015

\begin{tabular}{|l|l|r|l|}
\hline No & Tahun & Penerimaan & Ket \\
\hline 1 & 2010 & $1.991 .554 .997,-$ & \\
\hline 2 & 2011 & $3.201 .661 .872,-$ & \\
\hline 3 & 2012 & $3.313 .339 .565,-$ & \\
\hline 4 & 2013 & $6.291 .291 .530,-$ & \\
\hline 5 & 2014 & $2.588 .192 .970,-$ & \\
\hline 6 & 2015 & $2.162 .988 .234,-$ & \\
\hline \multicolumn{2}{|l|}{ Total } & $16.668 .029 .168,-$ & \\
\hline
\end{tabular}

Sumber: Laporan Baznas Kuantan Singingi

Badan Amil Zakat Nasional (BAZNAS) Kabupaten Kuantan Singingi dalam operasinya telah mendistribusikan dana zakat yang telah terkumpul mulai dari tahun 20102015 sebagaimana terlihat pada tabel berikut ini:

Tabel 2. Pendistribusian Zakat dari Tahun 2010-2015.

\begin{tabular}{|l|l|r|l|}
\hline No & Tahun & Pendistribusian & Saldo \\
\hline 1 & 2010 & $1.415 .350 .000,-$ & \\
\hline 2 & 2011 & $1.485 .737 .896,-$ & \\
\hline 3 & 2012 & $2.419 .956 .999,-$ & \\
\hline 4 & 2013 & $\mathbf{2 . 7 3 7 . 2 9 0 . 2 8 1 , -}$ & \\
\hline
\end{tabular}


Zakat untuk Pemberdayaan Ekonomi ...

\begin{tabular}{|l|l|r|r|}
\hline 5 & 2014 & $1.548 .985 .889,-$ & $1.039 .207 .081,-$ \\
\hline 6 & 2015 & $1.581 .135 .060,-$ & $581.853 .174,-$ \\
\hline
\end{tabular}

Sumber: Laporan Baznas Kuantan Singingi

Maka untuk lebih jelas lagi penulis mengelompokan pendistribusian dana zakat kepada beberapa golongan Asnaf menurut kebutuhan Asnaf mulai Tahun 2010-2015 untuk setiap tahunnya dan untuk lebih jelas dapat dilihat tabel dibawah berikut:

Tabel 3. Pendistribusian Dana Zakat Tahun 2010-2015

(Jumlah Penerima)

\begin{tabular}{|l|l|r|r|r|r|r|r|}
\hline No & Jenis & $\mathbf{2 0 1 0}$ & $\mathbf{2 0 1 1}$ & $\mathbf{2 0 1 2}$ & $\mathbf{2 0 1 3}$ & $\mathbf{2 0 1 4}$ & $\mathbf{2 0 1 5}$ \\
\hline 1. & Konsumtif & 2.878 & 3.068 & 2.980 & 2.301 & 1.946 & 2.042 \\
\hline 2. & Produktif: & 16 & 13 & - & - & - & - \\
\hline & $\begin{array}{l}\text { Pemberdayaan } \\
\text { Skill }\end{array}$ & 79 & 40 & 1 & - & 1 & 1 \\
\hline & $\begin{array}{l}\text { Pemberdayaan } \\
\text { Usaha }\end{array}$ & 2.973 & 3.121 & 2.981 & 2.301 & 1.947 & 2.043 \\
\hline
\end{tabular}

Sumber: Laporan Baznas Kuantan Singingi

\section{Pengelolaan Dana Zakat oleh Bazanas Kuantan Singingi}

Menurut salah seorang pengurus BAZNAS Kuantan Singingi dan melihat pelaporan Pendistribusian dana zakat oleh BAZNAS memang telah berpandukan kepada surat atTaubah ayat 60 dan pendistribuasian tersebut terbagi kepada dua model demi tercapainya pesan ilahi dalam pemerataan pendapatan dalam pemenuhan kebutuhan hidup hambanya.

Dalam penyaluran zakat menurut Muhammad Sayyid Yusuf (Yusuf, 2008: 171-172) menjelaskan, ZISWAF, Vol. 5, No. 1, Juni 2018 


\section{Fitrianto}

pendistribusian dana zakat berpedoman pada suarat atTaubah ayat 60 bahwa tujuan sebagai berikut:

a. Adanya program meminimumkan kefakiran dengan cara:

1) Memenuhi kebutuhan dasar dalam rumah tangga muslim (kebutuhan primer)

2) Memenuhi atau memberikan pendidikan skill untuk berkarya

3) Memenuhi atau menciptakan lapangan pekerjaan baru

b. Program meminimumkan kemiskinan dengan cara penyediaan anggaran rutin untuk organisasi pengurus harta zakat atau gaji bagi karyawan lembaga zakat (amil)

c. Anggaran pendidikan dan dakwah untuk meningkatkan keimanan dan pengetahuan keislaman para mualaf.

d. Anggaran kemanusian untuk menghapuskan penjajahan kemanusiaan, penindasan manusia oleh manusia dalam dunia kerja antara pekerja dan majikan, dan memerdekakan perbudakan serta keadilan di kalangan umat manusia

e. Anggaran pembebasan dan menghilangkan ekploitasi ekonomi, dan hutang menuju kemerdekaan ekonomi

f. Anggaran pembelanjaan agama dan negara dalam pengembangan ilmu dan teknologi untuk kemaslahatan umat

g. Anggaran untuk para ibnu sabil yang kesulitan dalam perjalanan untuk menuntut ilmu (beasiswa) dan program khusus untuk memecahkan kebutuhan umat yang mendesak.

Selain itu, pendistribusian zakat secara produktif pernah terjadi di zaman Rasullah SAW. Disebutkan dalam hadis riwayat Imam Muslim dari Salim Bin Abdillah Bin Umar dari ayahnya, bahwa Rasullah telah memberikan 
zakat kepadanya lalu menyuruhnya untuk dikembangkan atau di sedekahkan lagi. Dalam Islam dijelaskan bahwa yang berhak memberikan zakat yang bersifat produktif adalah yang mampu melakukan pembinaan dan pendampingan kepada para mustahiq agar kegiatan usahanya dapat berjalan dengan baik, di samping melakukan pembinaan dan pendampingan kepada para mustahiq dalam kegiatan usahanya, juga harus memberikan pembinaan dan intelektual keagamaanya agar semangkin kualitas keimanan dan keislamanya (Hasan, 2003: 37).

Pemberian modal kepada perorangan harus dipertimbangkan dengan baik oleh Amil. Apakah orang tersebut mampu mengelola dana yang diberikan oleh Amil. Sehinngga pada suatu saat dia tidak menggantungkan hidupnya pada orang lain, termasuk mengharapkan zakat. Apabila hal ini dapat dikelola dengan baik atas pengawasan dari Amil (bila memungkinkan) maka secara berangsurangsur, orang yang tidak punya (miskin) akan terus berkurang dan tidak tertutup kemungkinan, dia pun bisa menjadi pemberi zakat (muzzaki) bukan lagi sebagi penerima zakat (mustahiq).

Sebagaimana diketahui sasaran yang menerima zakat tidak hanya fakir miskin, tetapi masih banyak lagi sasaran lainya seperti fisabillah yang sangat luas cakupanya. Menurut islam zakat produktif itu dapat dilaksanakan asal saja pengolanya sudah dipikirkan lebih matang sebelum dikucurkan kepada masyarakat. Disamping itu hendaknya ada tuntunan atau panaduan lembaga pengelola zakat dalam pemberdayaan harta zakat untuk lebih produktif.

Maka oleh sebab itu, pola apapun dapat dibenarkan asal tidak bergeser dari tujuan untuk mengentaskan kemiskinan (kemelaratan) atau pembangunan ekonomi 


\section{Fitrianto}

umat secara menyeluruh dan umat Islam khususnya (Hasan, 2003: 40).

Menurut Abdul Al-Hamid Mahmud Al-Ba'ly, AlHamid Mahmud Al-Ba'ly dalam buku pemberdayaan harta zakat untuk pembangunan ekonomi umat dan kaitan dengan penyampaian kepemilikan harta zakat kepada mereka yang berhak terbagi menjadi empat, yaitu (alHamid, 2006: 84):

1) Pemberdayaan sebagian dari kelompok yang berhak akan harta zakat kepada mereka sehingga dapat memenuhi kebutuhan mereka. Selain itu juga dengan memberikan modal kepada mereka yang mempunyai keahlian dalam sesuatu, sehingga dapat meneruskan kegiatan profesi, karena mereka tidak mempunyai modal tersebut. Tentang hal ini, Imam Nawawy mengatakan dibukunya al-Majmu dari perkataan Jumhur Mazhab Syafi'i: Mereka mengatakan bahwa sesuai dengan kebiasaan, orang yang mempunyai profesi tertentu diberikan sesuatu dari harta zakat, dengan maksud agar mereka mengunakannya untuk membeli alat-alat yang mendukung profesionalismenya, baik sedikit maupun banyak. Dengan demikian, mereka mampu memenuhi kebutuhan hidup. Pemberian ini berbeda sesuai dengan perbedaan profesi, negara, waktu dan kepribadian masing-masing.

2) Pemberdayaan sebagian kelompok yang berhak atas harta zakat, adalah para fakir. Dengan memberikan sejumlah harta untuk memenuhi kebutuhan hidup mereka dan memberdayakan mereka yang memang tidak memiliki keahlian apa pun, baik kerajinan maupun perdagangan. Tentang hal Syaikh Syams alDin al-Ramly mengatakan di dalam buku Syarah alMinhaj al-Nawawy: Jika para fakir miskin belum mendapatkan pekerjaan sebagai penunjang hidup mereka, 


\section{Zakat untuk Pemberdayaan Ekonomi ...}

baik dengan frofesi maupun dengan berdagang, mereka diberikan bagian dari zakat secukupnya sesuai kebutuhan hidup dinegara mereka tinggal dan selama meraka hidup. Karena maksud dari pemberian tersebut hanyalah untuk memenuhi kebutuhan mereka yang belum terpenuhi. Jika umur mereka masih berlanjut, zakat diberikan tahun demi tahun. Akan tetapi, bukan berarti memberikan mereka seperti gaji dari hasil kerja, melainkan memberikan mereka sejumlah uang yang dapat digunakan untuk membeli rumah, yang kemudian mereka gunakan sebagain tempat bekerja, yang akhirnya, dapat terlepas dari ketergantungan terhadap harta zakat.

3) Pemberdayaan sebagian kelompok yang berhak akan harta zakat, yang memiliki penghasilan baru dengan ketidakmampuan mereka. Mereka adalah pegawai zakat dan para Muallaf.

4) Pemberdayaan sebagian kelompok yang berhak akan harta zakat untuk mewujudkan arti dan maksud sebenarnya dari zakat selain mereka yang disebutkan di atas.

\section{Simpulan}

Sebagai penutup kajian ini penulis menyimpulkan bahwa zakat adalah harta yang wajib dikeluarkan atau disisihkan oleh pemiliknya jika harta kekayaannya telah memenuhi satu nisab zakat dan kemudian mendistribusikannya kepada asnab delapan.

BAZNAS Kuantan Singingi dalam pengumpulan dana zakat dominan bersumber dari zakat profesi (gaji para PNS) di lingkungan pemerintah Kabupaten Kuantan Singingi. Sedangkan dalam pendistribusian, BAZNAS Kuantan Singingi mendistribusikan dana zakat dalam untuk membangun sosioekonomi umat seperti, pendistribusian harta zakat untuk konsumtif bagi para mustahik sesuai 


\section{Fitrianto}

dengan kondisi asnaf, seperti beasiswa, biaya berobat, rumah layak huni, honor amil, dan lainnya.

BAZNAS Kuantan Singingi dalam pendistribusian untuk produktif bagi mustahik yang mempunyai keahlian dalam usaha atau bisnis, seperti latihan bengkel kenderaan dan pemberian uang modal usaha bagi asnaf. Pendistribusian harta zakat dalam bentuk program produktif oleh lembaga pengelola harta zakat diharuskan mempunyai panduan program dalam penggunaan harta zakat untuk lebih produktif sehingga dapat meningkatkan pendapatan mustahiq dan pada akhirnya, mustahiq diharapkan menjadi muzaki pada masa yang akan datang.

\section{Daftar Pustaka}

A. Djazuli dan Yadi Janwari, Lembaga-Lembaga Perekonomian Umat, PT. Raja Grafindo Persada, Yagyakarta, 2002.

A. Qadri Azizy, Membangun Fondasi Ekonomi Umat, Pustaka Fajar, Yogyakarta, 2004.

Abdul Al-Hamid Mahmud Al-Ba'ly, Ekonomi Zakat Sebuah Kajian Monoter Dan Keuangan Syariah, Edisi I, PT. Raja Grafindo Persada, Jakarta, 2006.

Abdurrahman Qadir, Zakat Dalam Dimensi Mahdah dan Sosial, PT. Raja Grafindo Persada, Jakarta, 1998.

Adiwarman A. Karim, Bank Islam Analisi Figh dan Keuangan, PT. Grapindo, Jakarta, 2005.

Ahmad Supardi Hasibuan, Zakat Potensi Umat Terabaikan, Suska Press, Riau, 2013

Didin Hafidhuddin, Zakat Dalam Perekonomian Modern, Editor: Irwan Kelana, Cet. 1, Gema Insani: Jakarta, 2002. 


\section{Zakat untuk Pemberdayaan Ekonomi ...}

Dokumen Laporan Keuangan BAZNAS Kuantan Singingi Tahun 2010-2015

Gustian Juanda, Pelaporan Zakat Pengurang Pajak Penghasilan, Edisi 1, Cet. 1, PT. Raja Grafindo Persada, Jakarta, 2006.

M. Ali Hasan, Masail Fiqiyah 11, Zakat, Pajak, Asuransi Dan Lembaga Keuangan, Edisi Revisi, Cet. Ke-4, PT RajaGrafindo Persada, Jakarta, 2003.

M. Ali Hasan, Zakat Dan Infak Salah Satu Solusi Mengatasi Problema Sosial Di Indonesia, Edisi 1, Cet Ke-1, Kencana Prenda Media Group, Jakarta 2006.

Mahmood Zuhdhi Abd. Majid, Pengurusan Zakat, Cetakan 1, Dewan Bahasa dan Pustaka, Kuala Lumpur, 2003.

Mila Sartika, Pengaruh Pendayagunaan ZakatProduktif terhadap Pemberdayaan Mustahiq pada LAZ Yayasan Solo Peduli Surakarta. Jurnal Ekonomi Islam La Riba Vol. II, No. 1, 2008.

Muhammad al-Sayyid Yusuf, Tafsir Ekonomi Islam, terj., Murtadho Ridwan, Jahabersa, Johor Malaysia, 2008.

Muhammad, Zakat Profesi: Wacana Pemikiran Zakat dalam Fiqih Kontemporer, Selemba Diniyah, Jakarta, 2002.

Nurudin M. Ali, Zakat Sebagai Instrumen Dalam Kebijakan Fiskal, PT. Raja Grafindo Persada, Jakarta, 2006.

Rose binti Abdullah, Zakat Management In Brunei Darussalam: A Case Study. Seventh International Conference - The Tawhidi Epistemology: Zakat and Waqf Economy, Bangi, 2010.

Undang-Undang No. 23, Tahun 2011 tentang Pengelolaan Zakat. 


\section{Fitrianto}

Yusuf Qardawi, Hukum Zakat, Cetakan ke-10, PT. Pustaka Litera Antarnusa, Jakarta, 2002. 